\title{
Nova técnica para o tratamento cirúrgico da cabeça do pterígio - Exérese com álcool absoluto diluído a 50\%
}

\author{
New surgical technique for treatment of the pterygium head-Excision with 50\% ethanol
}

\author{
Rodrigo Angelucci ${ }^{1}$ \\ Rosângela Simoceli² \\ Marivaldo de Castro Oliveira ${ }^{3}$ \\ José Ricardo Rehder ${ }^{4}$
}

Trabalho realizado no Instituto de Olhos da Faculdade de Medicina do ABC-SP e no Centro Oftalmológico Ibirapuera - SP.

${ }^{1}$ Médico colaborador do setor de Retina e Vítreo da Disciplina de Oftalmologia da Faculdade de Medicina do ABC, Pós-Graduando, Mestrado Profissionalizante na Universidade Federal de São Paulo - UNIFESP.

${ }^{2}$ Médica orientadora do Excimer-Laser do Hospital Santa Cruz.

${ }^{3}$ Médico orientador do Excimer-Laser do Hospital Santa Cruz.

${ }^{4}$ Chefe e Professor Titular da Disciplina de Oftalmologia da Faculdade de Medicina do ABC e Professor Adjunto Doutor da Universidade Federal de São Paulo - UNIFESP.

Endereço para correspondência: Rodrigo Interlandi Angelucci, Rua Caconde 365, $6^{\circ}$ andar - São Paulo (SP) CEP 01425-011

E-mail: rodrigoangelucci@yahoo.com.br

Recebido para publicação em 27.05.2003

Versão revisada recebida em 06.11 .2003

Aprovação em 09.01.2004

\section{RESUMO}

Objetivo: Descrever nova técnica cirúrgica para o tratamento do pterígio utilizando álcool absoluto diluído 50\%. Método: A cabeça do pterígio foi submetida à exposição de gotas de álcool absoluto, diluído a 50\% em água destilada, durante 40 segundos e posteriormente removida com espátula de divulsão. Resultados: A excisão da cabeça do pterígio foi facilitada por plano de clivagem epitelial promovido pela aplicação do álcool diluído. O exame biomicroscópico evidenciou, após a cirurgia, superfície corneana com aspecto regular e homogêneo, o que pode contribuir para melhor qualidade de visão. Conclusão: O uso do álcool absoluto diluído a 50\% com água destilada pode ser utilizado como nova técnica cirúrgica para a exérese da cabeça do pterígio da região corneana.

Descritores: Pterígio/cirurgia; Etanol/uso terapêutico; Ceratectomia fotorrefrativa por excimer laser

\section{INTRODUÇÃ̃O}

O pterígio consiste em uma enfermidade do segmento anterior do bulbo ocular que afeta principalmente os habitantes das regiões equatoriais e, ainda que muito discutida a sua etiopatogenia, o clima árido e exposições à poeira, ventos e radiações ultravioletas da luz solar são fatores intimamente relacionados ao aparecimento desta doença ${ }^{(1)}$.

Caracteriza-se por um tecido fibrovascular, de forma triangular, que cresce na região interpalpebral da conjuntiva bulbar, mais frequientemente nasal, podendo estender-se para a córnea ${ }^{(2)}$.

Histologicamente, o pterígio apresenta-se constituído de tecido conectivo fibrótico frouxo com proliferação fibrovascular do epitélio e lâmina própria da conjuntiva bulbar, determinando alterações morfológicas do epitélio corneano e camada de Bowman, em decorrência da "degeneração pseudo-elástica" que as fibras colágenas denominadas elastóticas causam na área afetada ${ }^{(1-2)}$.

Diversas técnicas cirúrgicas para a excisão do pterígio já são consagradas, tais como avulsão, dissecção profunda, ceratectomia superficial, podendo ou não, estarem associadas à confecção de retalho conjuntival, transplante autólogo de conjuntiva, com membrana amniótica, esclera nua e outras. Todas essas cirurgias são realizadas com debridamento mecânico da cabeça do pterígio ${ }^{(3)}$.

Agentes químicos têm sido usados amplamente para a remoção do epitélio corneano e diferentes estudos têm demonstrado que essa técnica apresenta resultados com menores índices de perda de ceratócitos e apresentando maior regularidade da superfície corneana após a desepitelização ${ }^{(4-6)}$.

O tratamento cirúrgico do pterígio, nos casos em que não se consegue controle clínico satisfatório, permanece um grande desafio ${ }^{(7)}$. 
O objetivo deste trabalho é descrever uma nova técnica cirúrgica de remoção da cabeça do pterígio utilizando álcool absoluto a 50\% diluído em água destilada.

\section{MÉTODO}

\section{Descrição de técnica cirúrgica}

1. Instilação de gotas de tetracaína $(0,5 \%)$ colírio seguida de instilação de povidona 5\% no saco conjuntival;

2. Infiltração da conjuntiva no corpo do pterígio com $2,0 \mathrm{ml}$ de lidocaína a 2\% com epinefrina (1:10000) (Figura 1a);

3. Peritomia conjuntival peri-limbar, isolando a cabeça do pterígio de seu corpo (Figura 1b);

4. Demarcação da cabeça do pterígio com marcador de centro óptico Thornton ${ }^{\circledR}$, com diâmetro variável de acordo com as dimensões do pterígio (Figura 1c);

5. Instilação de gotas de álcool absoluto ${ }^{\circledast}$ (etanol 98\%) diluído a 50\% com água destilada (1:1) até o preenchimento do nível do marcador (Figura 1d);

6. Após 40 segundos absorve-se o álcool com uma esponja seca de celulose (Figura 2e);

7. Irrigação copiosa da área com solução salina balanceada (Figura 2f);

8. O epitélio é removido com uma espátula de divulsão, soltando a cabeça do pterígio da córnea (Figura 2g);

9. Resseca-se o corpo do pterígio da episclera com tesoura de Wescott e em seguida a conjuntiva remanescente;

10. Cuidadosa diatermia dos vasos episclerais hemorrágicos;

11. Escarificação do tecido subconjuntival hiperplásico remanescente com lâmina de bisturi número 15 .

12. Para o reparo da área de excisão do corpo do pterígio utilizou-se a técnica de retalho conjuntival com confecção superior, rotação e fixação do retalho na episclera com pontos simples com fio Vycril 8.0.

\section{DISCUSSÃO}

Métodos de remoção do epitélio corneano têm sido propostos, principalmente em cirurgia refrativa, com o intuito de facilitar a desepitelização e preservar a arquitetura das estruturas corneanas.

A técnica mais utilizada nos EUA consistia no debridamento mecânico do epitélio corneano com espátula sem corte ou com lâmina de bisturi, acarretando em pequenas irregularidades epiteliais e defeitos na camada de Bowman $^{(8-9)}$. Tal aspecto não foi observado na exérese da cabeça do pterígio com o uso do álcool diluído a 50\% em água destilada.

Etanol diluído de $10 \%$ até $30 \%$ são utilizados atualmente na técnica de PRK (Photo Refractive Keratectomy) para promover uma desepitelização corneana com exposição uniforme da camada de Bowman para posterior terapia com Excimer Laser $^{(10)}$.

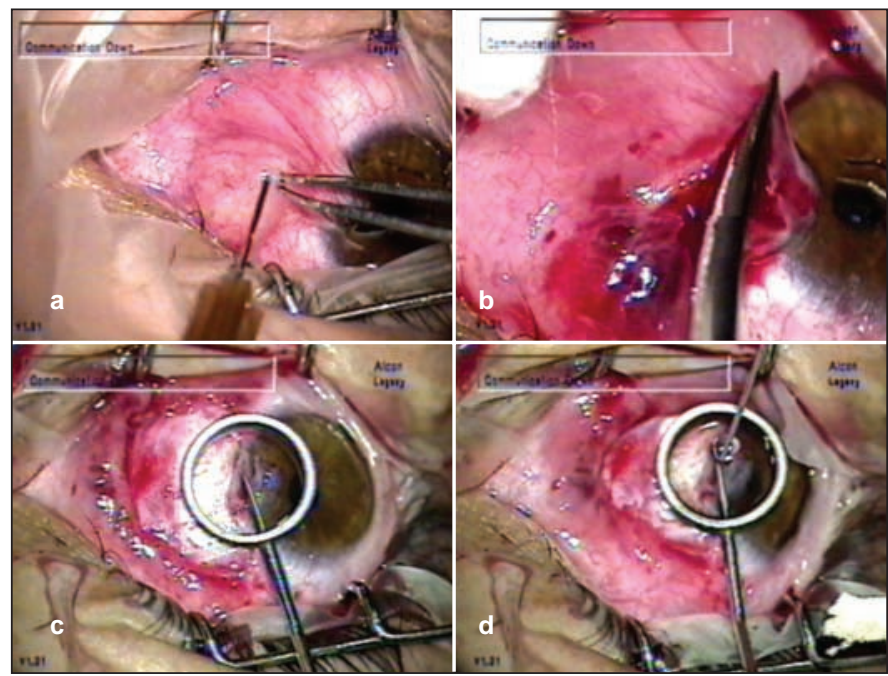

Figura 1 - a) anestesia subconjuntival; b) peritomia conjuntival perilimbar; c) demarcação da cabeça do pterígio; d) instilação do álcool

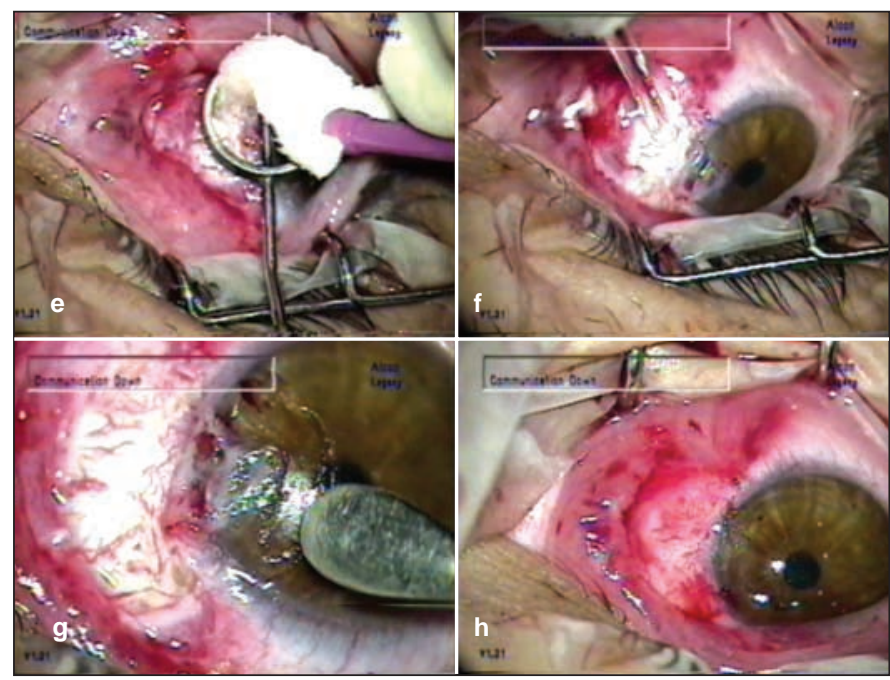

Figura 2 - e) absorção do álcool; f) irrigação da área exposta; g) divulsão epitelial com espátula; $h$ ) aspecto corneano final

Estudos relataram perda celular e inflamação corneana importantes com o uso do etanol a $100 \%{ }^{(11)}$. Entretanto outros estudos, utilizando etanol a $70 \%$, ressaltaram cautela em seu uso $^{(12)}$. No mesmo sentido, Helena et al descreveram menor perda celular e menor inflamação com etanol a $50 \%{ }^{(13)}$.

Abad et al, encontraram uma remoção epitelial mais rápida e mais precisa com a utilização do álcool quando comparada com o debridamento mecânico do epitélio corneano ${ }^{(14)}$.

Com esses dados, parece coerente admitir a segurança do uso do etanol diluído em água destilada a 50\% para a exérese da cabeça do pterígio da região corneana.

Um estudo mexicano comparando o uso do debridamento mecânico com o do álcool para a ressecção do epitélio corneano na cirurgia de PRK mostrou reabilitação visual mais rápida com o álcool e igual eficácia ${ }^{(15)} \mathrm{o}$ que foi observado nos casos submetidos ao procedimento cirúrgico proposto. 
A técnica cirúrgica descrita, utilizando álcool diluído a $50 \%$ com água destilada promoveu um plano de clivagem epitelial na córnea, facilitando, desta forma, a exérese da cabeça do pterígio com espátula de divulsão proporcionando uma superfície corneana regular e homogênea o que pode contribuir para uma melhor qualidade de visão.

\section{CONCLUSÃO}

O uso do álcool absoluto diluído a 50\% com água destilada pode ser utilizado como uma nova técnica cirúrgica para a exérese da cabeça do pterígio da região corneana.

\section{ABSTRACT}

Purpose: To demonstrate a new surgical technique for treatment of the pterygium head using 50\% ethanol. Methods: The pterygium head is exposed by ethanol, diluted $50 \%$ with distilled water, during 40 seconds and than removed with a surgical knife. Results: Pterygium head excision was rendered easier by ethanol application. After surgery, biomicroscopy showed a regular aspect of the corneal surface allowing a better vision quality. Conclusion: The excision of the pterygium head by using 50\% ethanol can be used as a new surgical technique for exeresis of the pterigyum head.

Keywords: Pterigyum/surgery, Ethanol/therapeutic use, Keratectomy, photorefractive, excimer laser

\section{REFERÊNCIAS}

1. Rehder JR, Hayashi H. Histological, histochemical and ultra-structural studies of gland like structures of human pterygium. Arq Bras Oftalmol. 1981;44 (1):1-4.

2. Hoffman RS, Power WJ. Current options in pterygium management. Int Ophthalmol Clin. 1999;39(1):15-26.

3. Lima ALH, Nishiwaki-Dantas MC, Alves MR. Doenças externas oculares e córnea. Rio de Janeiro: Cultura Médica; 1999. v.2. p.417-8.

4. Gundersen T. Herpes corneae with special reference to its treatment with strong solution of iodine. Arch Ophthalmol 1936;15(2):225-49.

5. Cintron C, Hassinger L, Kublin CL, Friend J. A simple method for the removal of rabbit corneal epithelium utilizing n-heptanol. Ophthalmic Res 1979;11(2):90-6.

6. Hirst LW, Kenyon KR, Fogle JA, Hanninen L, Stark WJ. Comparative studies of corneal surface injury in the monkey and rabbit. Arch Ophthalmol. 1981;99(6):1066-73.

7. Alves MR. Ressecção de pterígio e uso de Mitomicina C. Sinopse Oftalmol. 2001;3(2):27-8.

8. Thompson KP, Steinert RF, Daniel J, Stulting RD. Photorefractive keratectomy with the Summit excimer laser: the phase III U.S. results. In: Salz JJ, editors. Corneal laser surgery. Philadelphia, PA: Mosby, 1995. p. 57-63.

9. Piebenga LW, Malta CS, Deitz MR, Tauber J, Irvine JW, Sabates FN. Excimer photorefractive keratectomy for myopia. Ophthalmology. 1993;100 (9):1335-45.

10. Herrmann H, Hickman FH. Exploratory studies on corneal metabolism. Bull Johns Hopkins Hosp. 1948;82:225-50.

11. Campos M, Raman S, Lee M, McDonnell PJ. Keratocyte loss after different methods of de-epithelialization. Ophthalmology. 1994;101(5):890-94.

12. Nassaralla BA, Szerenyi K, Pinheiro MN, Wee WR, Nigam A, McDonnell PJ. Prevention of keratocyte loss after corneal deepithelialization in rabbits. Arch Ophthalmol. 1995; 113(4)506-11.

13. Helena MC, Filatov VV, Johnston WT, Vidaurri-Leal J, Wilson SE, Talamo JH. Effects of $50 \%$ ethanol and mechanical debridement on corneal structure before and after excimer photorefractive keratectomy. Cornea. 1997;16(5):571-9.

14. Abad JC, Talamo JH, Vidaurri-Leal J, Cantu-Charles C, Helena MC. Dilute ethanol versus mechanical debridement before photorefractive keratectomy. J Cataract Refract Surg. 1996;22(10):1427-33.

\section{Congresso Brasileiro de Catarata e Cirurgia Refrativa}

\section{1 d 14 de Mcio de 2005 Porte Segure - BA}

INFORMAC̣ÕES:

Consult Comunicação e Eventos

Tel./Fax: (31) 3274-1550

E-mail: comunica@consultcom.com.br 